\title{
Prevalence of Nutrient Canals in Digital Radiographs With Correlation to Systemic Conditions
}

\author{
Smitha Balla ${ }^{1}$, Sirisha Bavara ${ }^{2}$, Satish Alapati ${ }^{3}$ \\ Rajesh Damarasingu ${ }^{4}$, Prithvika Yerramalla ${ }^{5}$, Nivedita Ambavaram ${ }^{6}$
}

\section{Abstract}

\section{$>$ Aim:}

To determine if any correlation exists with incidence of nutrient canals in subjects with underlying systemic illness.

\section{$>\quad$ Patients and Methods:}

50 subjects were selected, which includes ten diabetic subjects, tenhypertensive subjects, ten post-menopausal women, ten periodontitis subjects, and ten subjects without any underlying systemic illness as control group.Radiovisiograph of all the patients was taken for evaluation of nutrient canals.

\section{$>\quad$ Statistical Analysis Used:}

Statistical analysis ofthe data was done using the statistical package for the social sciences (SPSS 16.0) using ANOVAanalysis. Differences were considered significant when $\mathrm{P} \leq \mathbf{0 . 0 5}$.

\section{$>$ Results:}

Among50patients, 41 patientsshowed nutrient canals, whereas ninepatients didn't show nutrient canals. Seven oftenpatients in Group I showed nutrient canals that accounts to $70 \%$ prevalence, eightof ten patients in Group IIshowed nutrient canals that account to $80 \%$ prevalence, and eightof ten patients in control group showednutrient canals that account to $80 \%$ prevalence and eight of ten patients in group $\mathrm{V}$ showed nutrient canals that account to $80 \%$ prevalence.

\section{$>$ Conclusion:}

Incidence of nutrient canals (NC) in the periapical radiograph can act as a supplemental diagnostic aid in detection of underlying systemic conditions like hypertension, diabetes mellitusand aiding the patient in his/her overall health and treatment planning.

Keywords:-

Nutrient

canals;

Diabetes;DiagnosticMarker;Hypertension;Systemic

conditions.

\section{INTRODUCTION}

Radiographs are essential diagnostic aids and are routinely used for investigating the diseases of teeth and bone. ${ }^{1}$ In dentistry, radiography is commonly recommended for the identification of conditionslike Caries, periodontal disease, and changes in the periapical region and also to assess osseous changes in the maxilla and mandible. In the literature, there are very few studies that correlate the less obvious radiographic appearances in the periapical radiograph to subclinical conditions of the oral cavity and systemic diseases. Specific radiographic findings can be of significance if evaluated; one such finding is the presence of nutrient canals. Nutrient canals are spaces in bones and are considered to be channels that conduit blood vessels and nerves. ${ }^{1}$ They are noticed more commonly in the anterior region of the mandible as radiolucent lines situated interproximal and inferior to the teeth. NC usually have a vertical direction rather than horizontal with varying width. ${ }^{2}$

Minimal effort has been made to correlate the prevalence of nutrient canals with hypertension, diabetes mellitus, periodontal diseases, tuberculosis, calcium deficiency, and coarctation of the aorta. ${ }^{3}$ There stay several nonreciprocal queries concerning $t$ he clinical significance and relationship, if any between the presence of nutrient canals and numerous pathologic conditions, and why they seem in some cases and not in others. $^{4}$ Hence, the present study was conducted preliminarily to know the incidence or prevalence of nutrient canals in healthy dentulous, hypertensive, diabetes, post-menopausal women and periodontitis patients and to determine if any correlation exists between them, and conjointly to know whether the presence of nutrient canals shall be used as a clue for the detection of hypertensive and diabetic patients.

\section{MATERIALS AND METHODS}

The study sample consisted of fifty subjects of either sex, between the age group of 21 and 70 years, from the outpatient department of Oral Medicine and Radiology, St. Joseph dental college. The selection of subjects was based on the following criteria and wasdivided into five groups:

Group-I (Control group) -consisted of subjects without any radiographic or clinical evidence of periodontitis and any systemic illness.

Group-II (Diabetic group) -consisted of known diabetes mellitus patients with a minimum duration of at least one year and without any other systemic illness. Moderate to severe cases of periodontal involvement were excluded.

Group-III (Hypertensive group) - consisted of known hypertensive patients, with the minimum duration of at least one year, and without any other systemic illness. Moderate to severe cases of periodontal involvement were excluded.

Group-IV (Post-menopausal): - post-menopausal women with a history of menopause for at leastsix months. 
Group-V (Periodontitis group) -consisted of patients with clinical and radiographic evidence of periodontitis like periodontal pockets, mobility, gingival recession, pus exudation, and without any systemic illness.

Selected subjects were clinically evaluated, and later radiographic procedures were carried out. As nutrient canals are observed most commonly in the Mandibular anterior

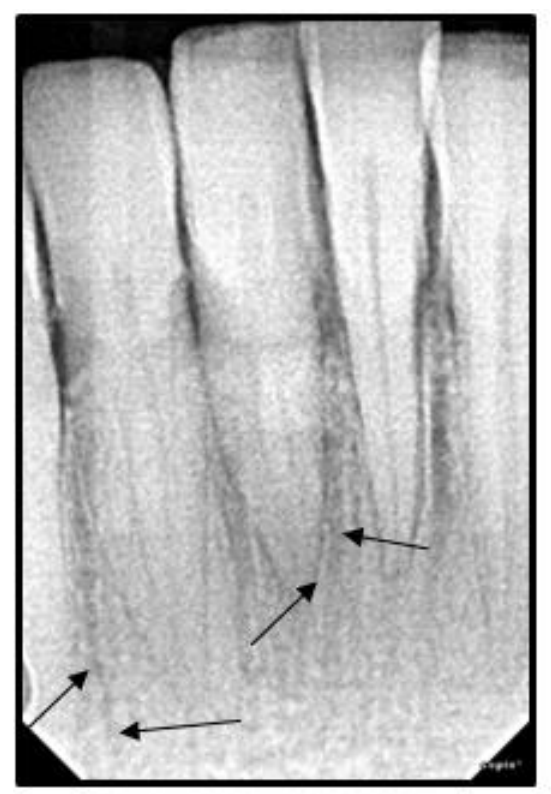

Fig 1

\section{Selection Criteria:}

- Inclusion criteria:

$\checkmark$ Known hypertensive

$\checkmark$ Diabetic

$\checkmark$ Post-menopausal

$\checkmark$ Periodontitis

$\checkmark$ Healthy controls without any systemic illness

- Exclusion criteria:

$\checkmark$ Bone disorders

$\checkmark$ Children

$\checkmark$ Maxillofacial trauma

$\checkmark$ Any pathology of jaws region, that region was chosen as the site of study. Radiographs were taken by paralleling angle technique using RVG and assessed for nutrient canals in mandibular anterior teeth, presence or absenceof radiolucent lines (nutrient canals) running vertically either in the interdental area or in the periapical region, and the total number of radiolucent lines present are recorded as nutrient canals (NC).

\section{Arrows indicates nutrient canals}

\section{RESULTS}

Prevalence of nutrient canals in the control group and other groups: The prevalence of Nutrient canals in groups I, II, III, IV, V were $70 \%, 80 \%, 80 \%, 80 \%$, and $80 \%$, respectively.

Overall Gender distribution (Table 1 and graph 1): Out of 50 subjects in the study, 15 were males, and 35 were females.

Gender distribution in groups(Graph 2): Out of 10 patients in group I six were males, and four were females, in group II five males and five females, group III two males and eight females, group IV included ten females and in group $\mathrm{V}$ included five males and five females.

Mean age of the entire studysample (Graph 3): The average age of the complete study sample is 40.7 years.

\begin{tabular}{|c|c|}
\hline Gender & No of subjects \\
\hline Males & 15 \\
\hline Females & 35 \\
\hline
\end{tabular}

Table 1:- Showing distribution of subjects based on gender 


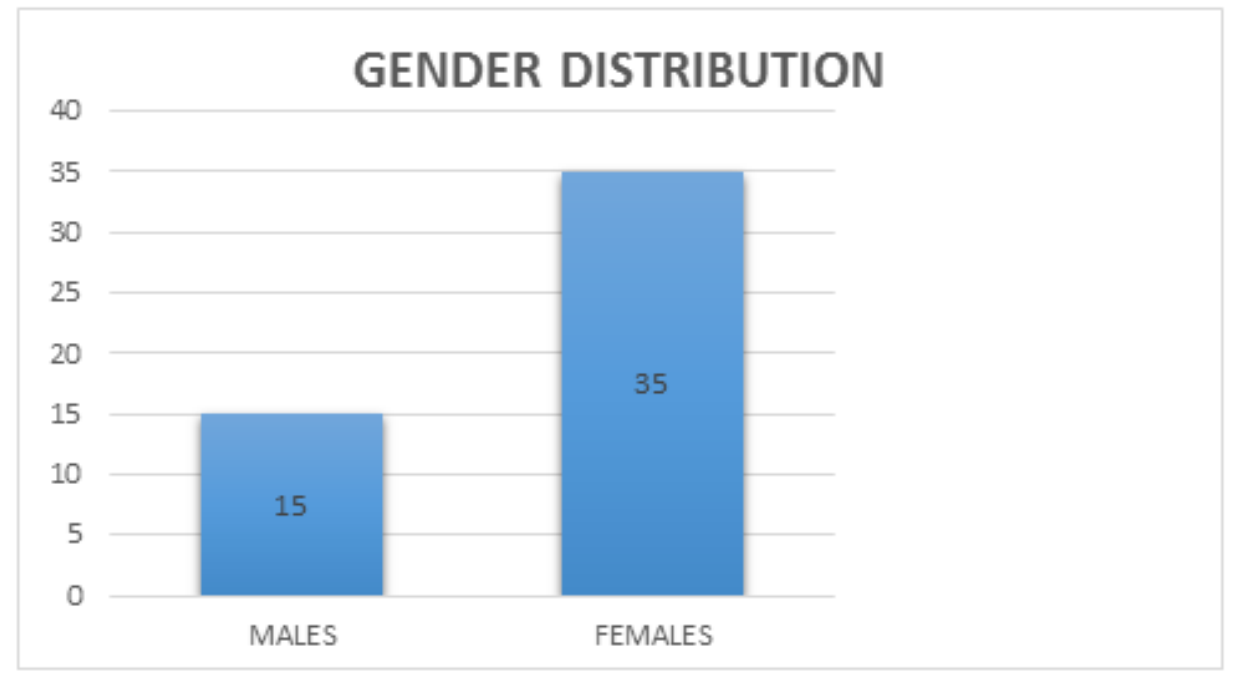

Graph 1

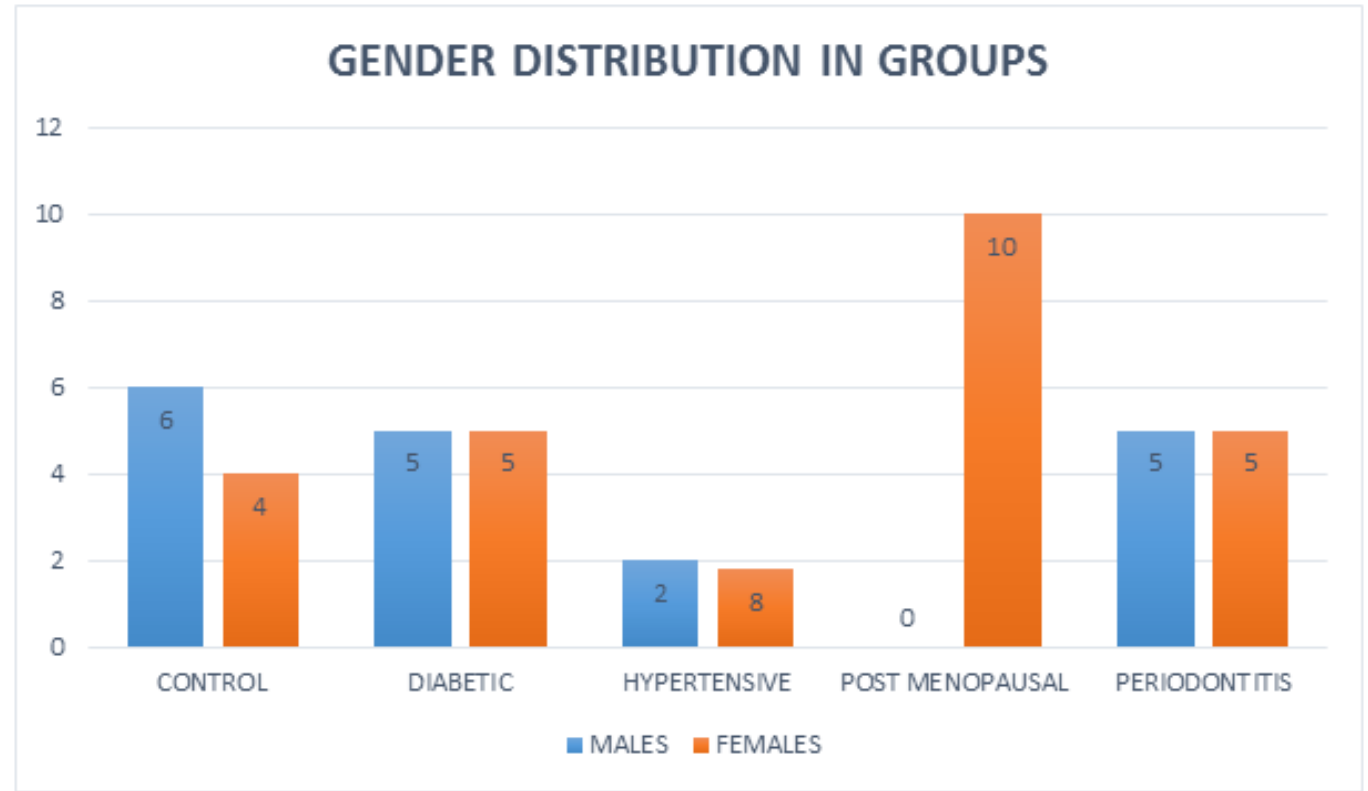

Graph 2

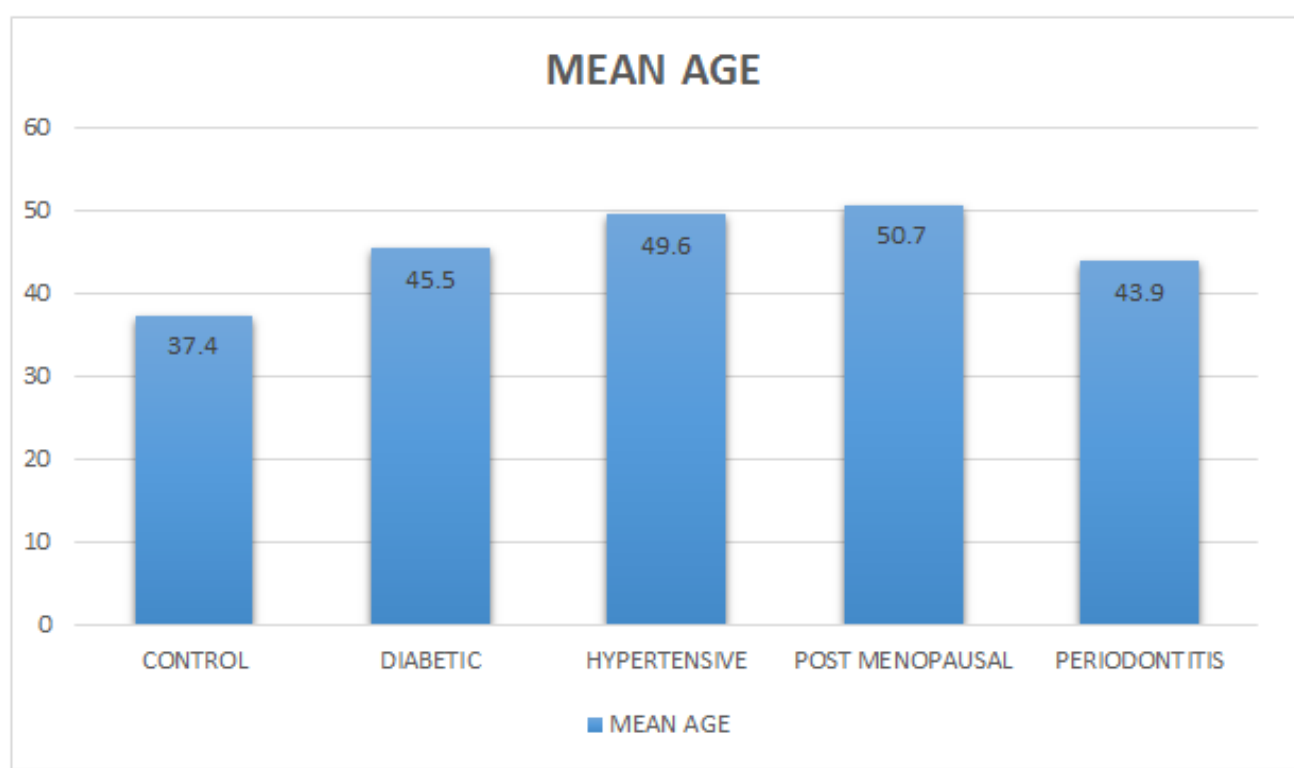

Graph 3 
ISSN No:-2456-2165

\begin{tabular}{|c|c|c|c|c|c|c|c|}
\hline & \multirow{2}{*}{$\mathrm{N}$} & \multirow{2}{*}{ Mean } & \multirow{2}{*}{ Std. Deviation } & \multirow[t]{2}{*}{$\begin{array}{l}\text { Std. } \\
\text { Error }\end{array}$} & \multicolumn{2}{|c|}{$\begin{array}{c}95 \% \text { Confidence Interval for } \\
\text { Mean }\end{array}$} & \multirow[t]{2}{*}{ p-value } \\
\hline & & & & & Lower Bound & Upper Bound & \\
\hline CONTROLS & 10 & .700 & .6749 & .2134 & .217 & 1.183 & \multirow[t]{6}{*}{0.099} \\
\hline DIABETIC & 10 & 1.400 & 1.0750 & .3399 & .631 & 2.169 & \\
\hline HYPERTENSIVE & 10 & 1.600 & .9661 & .3055 & .909 & 2.291 & \\
\hline POST MENOPAUSAL & 10 & 1.400 & 1.0750 & .3399 & .631 & 2.169 & \\
\hline PERIODONTITIS & 10 & 1.900 & 9944 & .3145 & 1.189 & 2.611 & \\
\hline Total & 50 & 1.400 & 1.0102 & .1429 & 1.113 & 1.687 & \\
\hline
\end{tabular}

Table 2:- Mean Number of Nutrient Canals in Each Group

\section{DISCUSSION}

Nutrient canals seen on the dental periapical radiographs are considered as conduits for nerves and blood vessels. NC stay the foremost enigmatic in their presence furthermore as an absence. Some researchers correlated the radiographic appearance of nutrient canals withdiabetes mellitus,periodontal disease, hypertension, rickets, and calcium deficiency.

Several studieshave been carried out to ascertain the role of NC in both health and disease. Predominance of NC in the mandibular anterior region was demonstrated to the following facts:

$>$ Thin alveolar process

$>$ Horizontal trabecular pattern

$>$ Less bony support of cortical and cancellous bone

$>$ Liabilityof irritation from calculus and trauma.

The present study was conducted to evaluateif any correlation exists between them, and also to determine whether the presence of nutrient canals can be used as a clue for the detection of diabetic and hypertensive patients.

In this study, the lower anterior periapical radiographs of 50 subjects of either sex, with the age group of 21 and 70 years are included. The study sample was divided into five groups, which include diabetic, hypertensive, periodontitis, post-menopausal, and the control groups with ten patients each and evaluated for the presence of nutrient canals.

Our results showed the prevalence of Nutrient canals in groups I, II, III, IV, V were $70 \%, 80 \%, 80 \%, 80 \%$, and $80 \%$, respectively.

The prevalence of nutrient canals in the hypertensive group was higher in comparison to the control group, which is inconsistent with the previous studies. The principal effects of hypertension are arteriolar dilatation, hypertrophyand hyperplasia of the endothelium and arterial sclerosis. In arterial sclerosis, there is a thickening of the arterial wall and luminal narrowing, which may lead to more collateral vessel formation inflating the increased incidence of nutrient canals in hypertensive patients.
Nutrient canals were observed in $80 \%$ of the individuals of the periodontitis group. This proportion is high compared to the results published by Ryder (19.2\%), Sweet (15.8\%), and Patel and Wuehrmann (42.5\%).Thedevelopment of new blood vessels with metabolic alteration of the bone might be related to the disease process and the better visibility of nutrientcanals with sclerosis in the trabecular bone.

The incidence of nutrient canals in diabetic patients was $80 \%$ compared to the control group,whichwas $70 \%$. Findings which are reported by Wuehrmannand Patel (58.4\% incidence in diabetic patients to that of $43.9 \%$ incidence in non-diabetics) and Donta andPierrakou(there was $75.34 \%$ incidence in diabetics patients to that of $41.6 \%$ in non-diabetics) the prevalence of $\mathrm{NC}$ was high in the present study.

According to Isselbacher et.al Insulin deficiency has the proliferative action on the endothelium, which would lead to the formation of collateral vessels. In diabetic patients also, the process of atherosclerosis can be seen, leading to lumen narrowing. So there is a tendency of collateral vessel formation as a compensatory mechanism, which leads to an increased incidence of nutrient canals. This implies that, though the medication delays the systemic effects, it cannot be prevented totally.

\section{CONCLUSION}

Prevalence of nutrient canals (NC) can act as a supplemental diagnostic aid for detection of underlying systemic conditions like hypertension, diabetes mellitus, etc. and aiding the patient in his/her overall health and treatment planning of such diseases.

But a bigger sample of individual groups is required to associate comprehensive data of little variations consistent with age, sex, duration and frequency which could help to make better diagnosis and treatment decisions. 


\section{AUTHOR CONTRIBUTIONS}

SmithaBalla, contributed to conception, design, data acquisition, analysis and interpretation, drafted and critically revised the manuscript; SirishaBavara, contributed to conception, data analysis, and interpretation, drafted and critically revised the manuscript;SatishAlapati, contributed to conception, design, data acquisition, and interpretation, , drafted and critically revised the manuscript the manuscript; Rajesh Damarasingu,contributed to conception and design, data acquisition and critically revised the manuscript;PrithvikaYerramalla,contributed to conception and design, data acquisition and critically revised the manuscript;NivedithaAmbavaram,contributed to conception and design, data acquisition and critically revised the manuscript;. All authors gave final approval and agree to be accountable for all aspects of the work.

\section{ACKNOWLEDGMENTS}

The authors received no financial support and declare no potential conflicts of intrest with respect to the authorship and/or publication of this article.

\section{REFERENCES}

[1]. Patni VM, Merchant GJ, Dhooria HS. Incidence of nutrient canals in hypertensive patients: A radiographic study. Oral Surg Oral Med Oral Pathol 1985; 59:206-11.

[2]. White SC, Pharaoh MJ, editors. Oral radiology, Principles and interpretations. 5th ed. St. Louis: Mosby; 2004. p. 184-5.

[3]. Patel JR, Wuehrman AH. A radiographic study of nutrient canals. Oral Surg Oral Med Oral Pathol 1976;42:693-701.

[4]. Kishi K, Nagaoka T, Gotoh T, Imai K, Fujiki Y. Radiographic study of mandibular nutrient canals. Oral Surg Oral Med Oral Pathol 1982;54:118-22. 